\title{
A Qualitative Study of Communication between Young Women with Disorders of Sex Development and Health Professionals
}

\author{
Caroline Sanders ${ }^{1}$ and Bernie Carter ${ }^{2}$ \\ ${ }^{1}$ Alder Hey Children's Hospital NHS FT, Liverpool, UK \\ ${ }^{2}$ University of Central Lancashire and Children's Nursing Research Unit (UCLan), Alder Hey Foundation Trust, Brook Building 437, \\ Preston PR1 2HE, UK \\ Correspondence should be addressed to Caroline Sanders; caroline.sanders@alderhey.nhs.uk
}

Received 18 November 2014; Revised 18 December 2014; Accepted 22 December 2014

Academic Editor: Violeta Lopez

Copyright (c) 2015 C. Sanders and B. Carter. This is an open access article distributed under the Creative Commons Attribution License, which permits unrestricted use, distribution, and reproduction in any medium, provided the original work is properly cited.

\begin{abstract}
Background and Objectives. Health communication is a critical aspect of care for both providers and recipients having a direct influence on engagement and outcomes. Communicating which in this context includes talking and listening in order to share information or support young women to understand their DSD can be difficult especially since the topic area is sensitive. Methods. In this qualitative study thirteen young women (aged 14-19 years) with a disorder of sex development who engaged with health care professionals were purposively recruited between 2011 and 2012 from three specialist centres across the United Kingdom. The young women either were interviewed or completed a diary about their experiences of communication with a range of health care professionals. An interpretative phenomenological approach was used to analyse these data. Results. By analysis of data the young women were able to clearly articulate the qualities and skills health professional needed in relation to communication. Two main categories focused on the duty in which professionals have to share information and their role in supporting young women to manage this information. Discussion and Conclusion. The study results revealed that these young women with a DSD expected to meet skilled professionals who could recognise the emotional aspects of dialogues in the short and longer term.
\end{abstract}

\section{Introduction}

Disorders of sex development (DSD) are life-long conditions, usually diagnosed at birth or during adolescence, affecting the individual physically, emotionally, and psychosocially thereby influencing psychosexual development $[1,2]$. The group of affected individuals is large and heterogeneous with management strategies in the last decade focusing on a more holistic multiprofessional approach [3]. Core to a change in care delivery systems was that parents, young people, and clinicians should be jointly involved in treatment decisions [4]. Medical interventions within this population focus on investigations to determine underlying pathology, genital surgeries, and interventions such as vaginal dilatation, pharmacological management, and more recently assessment and management of psychological well-being [2]. While genital surgery in infancy is a contentious issue [5] those born before 1999 are more likely to have experienced genital surgeries as a result of assignment to either male or female sex of rearing [6]. It is unclear if the choices and decisions made by parents about early surgery and management are discussed with their adolescent [7].

Health dialogues are one aspect of communication and operate within complex environments and across different groups, with parents often being considered as proxy information providers. For complex conditions identified in infancy or adolescent parents, young people and professionals have to be able to share understanding and appreciate and respect other's beliefs, values, and expectations [8]. The challenge for health professionals and parents is how or when to share complex information about DSD and its management with these young women as they mature.

For all young women, including those with DSD, adolescence is a stage when questioning self, life, and purpose is more likely [9]; emotions, uncertainty, worry, and discovery are further heightened in young women with DSD as they 
begin to develop a sense of "who they are." Therefore sharing and receiving information can be emotive [10]. Face-to-face dialogues between young people and health professionals often take place in clinical environments, which some young people consider as being too focused on medical management and, therefore, nonconducive to good communication [11]. These dialogues may focus on diagnosis or transfer of knowledge about symptoms [12] which elicit varying levels of contribution from young people depending on the communication skill, attributes, and disciplinary background of the professional involved [13]. For some young people a more informal approach and style that mimics everyday chatter can be helpful; nurses are reported as skilled in this approach [14]. Good communication between professionals and young people and their parents can facilitate engagement resulting in the information shared being better understood by all parties [15]. While it is essential that health professionals share information with these young women, the type and impact of the information shared needs to be recognised since the emotional experiences that ensue as a result of communication may have the capacity to influence future decision-making behaviours.

Being cognizant of the complexity of communication in healthcare, our study aimed to explore the experiences of young women with DSD in terms of their encounters with health care professionals within a range of healthcare settings in order to better understand the types of communication they were having with professionals.

\section{Methods}

Interpretive phenomenological analysis (IPA) was used as it facilitates an in-depth exploration of people's lived experiences, promotes a close examination of how people make sense of those experiences over a period of time [16], and generates subjective experiences of communication styles, which could be presented as descriptive everyday language [17].

2.1. Recruitment, Sample, and Ethics. Participants were recruited from three sites across the United Kingdom, invited via the clinician leading their care. Purposive sampling aimed to recruit a minimum of three young people between the ages of 12-21 years from each site whilst also reflecting a range of DSD conditions (as described in the DSD consensus guidelines [18]).

The lead National Health Service (NHS) Ethics Committee approved the study with site-specific approval being granted from collaborating trusts and the NHS Research Scotland Coordinating Centre and adopted by NIHR (UKCRN ID 10400). Participants younger than 16 years of age provided assent but their parents had to provide written consent for them to participate.

2.2. Data Collection. Between 2011 and 2012, data were collected either via face-to-face interviews at the participant's home or via a postal diary completed by the young person. The young people interviewed were given the choice of being interviewed on their own or accompanied by a parent or
TABLE 1: Range of DSD conditions.

\begin{tabular}{ll}
\hline \multicolumn{2}{c}{ Range of DSD conditions ( $n=$ omitted to maximise patient } \\
anonymity)
\end{tabular}

another supportive person. Both the semistructured interview and the diaries explored how the young people communicated with health professionals, their experiences of positive and negative encounters, and their motivations for seeking professional advice and the beliefs that influenced their actions.

2.3. Data Analysis. The diaries were treated in the same manner as the interview transcripts and imported in to Atlas-ti (version 5). All transcripts were incorporated into a paper "scrapbook" with wide side margins [19] and analysed using an IPA approach [16]; the lead researcher worked through analysis of the transcripts in the order they were collected. The researcher kept a reflexive notebook in which to write critical reflections and observations, which in turn formed part of the discussions with the research team, which included a group of four young women with DSD. Descriptive analysis explored the subjective experiences of professional communication styles and reported feelings generated in the young people. In-depth analysis involved examining semantic content and language focusing on words, phrases, the use of metaphors, and corporeality within the context of all conversations about their DSD. This level of analysis was shared and discussed within the research team in order to facilitate in-depth interpretation. In-depth analysis examined the data within the context of how young women made sense of the information communicated to them and the impact this had on self and others. Pseudonyms are used to protect the identity of the young women.

\section{Findings}

3.1. Descriptive Analysis: Summary of Participants. Fourteen young people returned signed consent forms resulting in five diaries and eight interviews; one participant subsequently chose not to participate. All participants $(n=13)$ were aged between 14 and 19 years, median age 16.8 years. The range of DSD conditions the young women reported is presented in Table 1. While one young woman believed participation might be upsetting the process of writing a diary was cathartic and sharing the contents was liberating; she wrote that it "helped me get it off my chest."

The young women were able to express emotional responses to their experiences, for example, feeling happy, sad (withdrawn), frustrated, worried, anxious, and frightened. Engagement in dialogues with professionals and experiences of communication were complex and included a range of 
healthcare professionals from hospital doctors, nurses (hospital and school), psychologists, phlebotomists, and general practitioners. From the young women's experiences it became clear that in order for health professionals to deliver and facilitate communication the young women believed a skill set was necessary. The skills necessary are highlighted in Table 2 with examples from the transcripts; these included the following:

(i) professional knowledge of DSD and the life course of DSD conditions;

(ii) engagement in dialogue was more likely if the professional was well-known to the young women;

(iii) active listening skills, good nonverbal communication, and verbal skills were important when sharing information and making the young women feel valued;

(iv) professional's ability to check out understanding and give the young women time and a safe space in which to formulate questions;

(v) to respect privacy and confidentiality within the dialogue but also between the young person and their parent.

Grace captured many of the skills professionals needed when summing up her positive experience with a nurse she had come to know over a period of time.

"I guess [the nurse] was down to earth. Instead of assuming or thinking that she knew better, she was more than qualified, she did know better but she listened. She took the time to listen to you to find out what was wrong. So she could feel on some level in that brief moment when you tell her what's wrong she then stops becoming your doctor or nurse and starts becoming another patient in the way she tries to understand it."

\section{In-Depth Analysis}

As well as professionals needing a range of verbal and nonverbal communications skills to facilitate communication these young women believed that health professionals had a duty to share information as well as support them to manage information. The following sections report these two categories in greater detail.

4.1. Duty to Share Information. The young women wanted to learn more about their DSD but they were aware that this learning could occur in ways that were positive and helpful or were poorly communicated and unhelpful. They talked of times when even helpful health professionals had only shared limited amounts of information. The young women explained how their parents' voices often dominated clinical encounters allowing them few opportunities to participate in conversations about themselves and their own bodies. The young women were unsure whether it was health professional's duty to share information with them. This resulted in them sometimes being afraid to initiate conversations with professionals, as they were concerned that asking a professional might be seen as being disrespectful to their parents.

These young women believed that healthcare professionals expected that their parents would be knowledgeable, skilled, and able to share information with them; for example, Katherine summarised a long dialogue with "they kind of left it for my mum to explain as I got a bit older." This professional reliance on parents as a source of information was, for some young women, unacceptable resulting in them expressing their anger. Five young women were explicit about wanting to understand "everything that happened, even when I was younger" recognizing the limitations of their parents' memories, ability, and understanding. They described their parents' subjectivity as problematic, aware that their parents decided what information to share, omit, or withhold, for example, " $a$ lot of the time you hear the stories and later on you hear little details and it's like you are making a puzzle...let's tell them about this but that's not important, we'll leave that bit out, but it could be [important] to me" (Carla). The young women were keen to learn about themselves, expecting health professionals to communicate in ways which could allow them to better conceptualise early surgeries in order for them to understand how these actions affect their future.

The young women believed that their parents, usually their mothers but sometimes other family members, had a pivotal role in working in partnership with professionals to share their DSD story with them. They explained that many conversations with their parents were opportunistic, parentled, and often confusing. These conversations usually arose before a meeting with a health professional giving the young women little time to deal with information. Carla recalled feeling surprised and confused at overhearing her mother talking to a friend about gender uncertainty as the reason why Carla had hospital visits. When asked about health professionals' roles in shaping her understanding, she talked of them as being a negotiator going on to describe how they could put simple strategies into practice that would be helpful when parents were unable to sustain, retain, or share information: "Yes...I think it's important that they [health care professionals] do put it [together]... .let's make sure she knows what's happened, she or he you know...I think if it was like a diary [that they] put together so that it gets done properly...[because] parents will be like - 'Oh yes we'll do it' and they'll do the first few and then it's like - 'Oh we are not going to do it anymore, [we] can't be bothered."

Recollection of access to what young women consider was "the right" professional was variable. Those young women that had experienced transition from paediatric services talked about the impact of seeing new health professionals and the limitations this had on conversations. Furthermore receiving summary letters addressed to themselves after clinic appointments for those aged over 16 years was a new experience. These letters could include new information that the young women were not aware of which left them unsure of who to approach for clarification.

4.2. Support to Manage the Information. Supporting young women with DSD requires a comprehensive approach, which includes both sharing information and helping young women 
TABLE 2: Necessary professional skills: evidenced in the subjective experiences of the young women.

Skills, qualities, and attributes that promoted communication between the young women and healthcare professional

Knowledge about DSD
Evidence in everyday language taken from the transcripts of the young women to highlight both positive and negative experiences of communication with healthcare professionals.

Grace shared her engagement with one professional that developed over time "She has come across the worst in people and the best in people... [she was] someone who tried to explain it with very little words because the more shock you are in the less focus time you have." Martha explained that as a result of sharing knowledge professionals "have changed the way I think about myself [by explaining it]. . I see myself as more confident and more relaxed about things and I can count on the health professionals they have always had time to talk to [me] and it has always made a good change."

"We just had a good friendship. It wasn't just like when you go to the doctor and you sit down and you tell him what's wrong and they're like - 'ok you take this medicine and you'll be fine' - type of thing. It was more than that. You could sit and have a conversation with him about anything and he wouldn't dodge or judge you" (Florence). Contrary to this experience Louise described her "worst experience was talking to someone I had just met." Harriet explained her frustration, "you get used to the doctors and then they all change."

Evelyn described her school nurse as "a good listener because she was the one who sorted me out" she continued to recall experiences with nurses when she had surgery, "Just their whole attitude towards you, their body language. .I've seen adults going into hospital and they don't use eye contact, and they are just get it over and done with stuff, but they [nurses] actually like look you in the eye and they smile at you and it's nicer." "They don't interrupt you and they just sit and listen and they let you speak... ask if you have any questions, make you feel comfortable and speak to you, have eye contact with you, they tell you the same story and not mixed up stories" (Brenda).

Annie recalled that "it's like the tone of his voice" that would scare her and [the doctor] "never asked if we've got any questions."

Florence recognized times when sharing and listening were incongruous "You can tell if someone's speaking really, really fast about something and they're like talking, talking, talking, and then they're like - right do you get it? You're like-Mm yes, but really you don't, and they're like - right ok. Then they just keep talking. That's how I can tell, you really don't, and you're not that interested."

"[That professional] took it all in and gave me good advice" resulting in Harriet feeling more at ease, she continued to offer, "I think trust is either there or it's not there to be fair." Trust is very important since it is core to engagement as Grace shared "I just won't speak openly unless I think I can trust them." Dina talked of her disengagement and how she would just "nod and smile" when she felt "a small fear of judgment" since she felt clinic could be "nerve racking. . . frustrating and embarrassing." While Evelyn recalled feeling angry when "some of the people didn't believe me [that I was in pain]" which left her feeling "angry and a bit annoyed."

Katherine recalled "I didn't really understand at the time why I was having the operation and how big it was going to be." This left her unprepared and in pain emotionally and physically she wrote about no one asking her if she understood what was going to happen. Imogene shared that "when people explain things to me clearly I stop being scared. . I expect people to talk to me in a way that I can understand, medical words don't mean anything to me." "[Some professionals] explain things but I just don't understand a word of it. They come out with all the technical words and stuff and I just don't understand it so I just say 'yes.' I don't say - 'can you explain that so I can understand it'? I don't say that, I just say 'yes." (Harriet). Martha had thought about this and suggested that "to improve [my understanding] they should do a survey on what they have just been talking about to make [me] more knowledgeable."

Grace recognised the importance of feeling safe "It [clinics] can't be all scary for the kid, it's got to be sort of quite chilled and mellowed out, not all shirts and ties because when you are in the hospital and you see the big brown boots with the shine on them, the tie, the belt, that's it! You don't want to be there." 
TABLE 2: Continued.

Skills, qualities, and attributes that promoted communication between the young women and healthcare professional

Providing privacy and maintaining confidentiality
Evidence in everyday language taken from the transcripts of the young women to highlight both positive and negative experiences of communication with healthcare professionals.

Evelyn explained that "it's a bit embarrassing to speak about it. . you still need a bit of privacy, you don't want everyone knowing your business about the problems you have."

Grace recalled it took time for her to build confidence in others; she recalled one professional and how this developed over time, "She had a way with me, she found out what I liked to do most and then she went and took me out to do them before she started speaking to me. Now that I think about it she was rather clever." to manage it. None of the young women recalled their parents talking to them either before or during adolescence about their emotions or mood or the possibility of accessing psychological support as a consequence of their DSD. The young women were not critical or angry towards their parents or professionals but reflected that psychological support may have been helpful at key times, such as when they realized what having DSD meant and when they were coping with uncertainty and difference.

Several young women believed that professionals familiar with them were more perceptive of the degree of information they should share than those they saw infrequently. For those that were faced with a professional who was less in tune they tried to balance learning about themselves and found ways in which to cope with information overload, as Annie recalls, "If I've had a bad experience [doctors telling me too much stuff] I just stop listening to them and just switch off." Some adopted protective measures such as appearing disinterested in clinic; this resulted in the conversation tailing off meaning that they did not have to listen to information they were unprepared for. Being "ready" to hear information and engage with professionals happened as a consequence of getting older, having more understanding, and becoming more mature. This resulted in a greater understanding and, as Louise described, "inevitably changed the way I talk with healthcare professionals."

Determining when they were mature enough was something the young women acknowledged as a double-edged sword. Grace struggled to explain how she shifted from "not caring" to wanting information "slowly." For Grace there was an expectation that the professional she saw could help her by making the news understandable and ensure she had support afterwards to think through the consequences of the new information. At times, several young women described being angry at how information was shared; this inevitably resulted in them feeling frustrated. These young women were not always able to articulate how this could have been better. A couple of young women described that after disclosure or discussions about vaginal dilatation they believed that specific professionals had not recognised they were feeling unsupported despite their consultations being emotional. Brenda talked about being surprised and sad when information about her uncertain sex at birth, including her male name, was casually raised in an outpatient clinic during a conversation between her mother and a health professional. On reflection she considered that neither her parent nor the professional had recognised her emotions, understood her withdrawal from the dialogue in clinic, or found a way to support her to reconcile this information. It was only overtime that she began to make sense of her uncertain sex at birth, what this meant to her, and how she felt about herself and her body.

\section{Discussion}

The young women in this study not only faced the usual tasks of adolescence but also experienced additional dilemmas and uncertainties resulting from the fact that they were beginning to ask questions and explore what they understood about themselves including the implications of DSD and the consequences of early surgeries or sex uncertainty. As with any health communication they had expectations in how they hoped they could learn about themselves and their condition including what it meant to them in their future. Good communication was essential if the young women were to engage in consultations with professionals providing an opportunity for them to learn about their DSD or have the confidence to ask questions. The skills of the communicating professional were important since positive experiences had the capacity to engage the young women. More negative experiences of communication elicited emotional responses of anger and sadness or were expressed as feeling overwhelmed; these emotions often resulted in disengagement within the consultation. While the professional's ability to recognise these responses was outside of the scope of this study a few young women spoke about the professional's lack of awareness.

There were groups of professionals who demonstrated their skill in dialogues with young women; they were from different disciplines within hospital and community settings. In these circumstances the young women were more likely to ask questions and be receptive to learning new information or revisiting questions about themselves. The emotional responses from these young women were often described in secondary terms as "comfortable" and "safe." The information exchange that dominated these communication encounters was often with professionals the young women had known over long periods of time. The need for professionals to be good communicators [20], to be respectful and mindful of the young women's privacy [12], and to provide the opportunity 
for the young person to flourish and master confidence to ask questions [21] is not a new idea within health communication. It was reassuring to identify that young women with DSD required access to a skilled communicator as much as other young people experiencing health care. However, the sensitivity of the information that needed to be communicated to these young women is likely to be significant and professionals may benefit from additional training and support in managing complex and difficult consultations.

Not all the young women considered themselves to be knowledgeable about their condition or able to talk to professionals about their DSD. Being uninformed about their condition has been reported in other studies of young women with DSD [22]. However, how professionals help young women address uncertainty about their condition and future bodily limitations remains a challenge as other possible barriers exist; for example, Karkazis [23] noted that some young people with DSD have learnt from their parents that questioning is "off limits." While the young women in this study were cognizant that their parents may not have the knowledge, skills or memory to be suitable teachers about DSD they harboured a deep sense of needing to know what had happened to them. As they grew up they sought information from health professionals in a language that was helpful, without medical words and terms. When the dialogues between young women and professionals shared a common language they led to increased understanding or "moments" for several young women when what they had previously learnt or talked about with professionals suddenly made sense; these were described as "get it now" events, which is similar to the findings from Kimberley et al. [24] work.

Supporting young women with DSD requires a comprehensive approach, which includes sharing information and helping them to manage it. By sharing information and ensuring that these young women feel supported it is anticipated that they develop skills in self-care, which includes having an understanding of the life-long implications of their birth conditions. The analysis by Kirk et al. [25] concludes that there is no evidence that self-care interventions delivered by parents alone or delivered only in hospital settings are effective. Therefore, both professionals and parents need to explore creative approaches to information sharing and provide opportunities for these young women to share experiences and ask questions. While none of the young women in this study spoke about using health or support groups to access information this is an area that would warrant further study since there is evidence to suggest these approaches are effective in promoting self-care in young people with chronic conditions [25].

\section{Conclusion}

The young women in this study felt strongly that professionals, in partnership with their parents, had a duty to share information with them about their early childhood interventions as well as their DSD condition. Health professionals need to be sensitive to the young women's responses to talking about personal issues and care needs to be taken to follow up the young woman's understanding, coping, and mood following the sharing of information. Insightful professionals will need to be able to juggle information priority, understand the social context and implications of sharing what could be "life changing" information, and be able to find adaptive and creative ways in which to share complex material. While professionals from different background and disciplines were involved with these young women there were expectations that they would be skilled communicators able to engage the young women in dialogues. Active listening skills, building trusting relationships, and respecting privacy needed to be balanced against the detail and depth of information and timing of dialogues. Currently recognised training programmes for health professionals working in this area often comprises of study events or conference meetings. While further training in enhanced communication skills could be helpful more focused training in some of the subfields of psychology such as human development, social behaviour and cognitive process may further skill the mutliprofessional workforce to support this group of patients. Early clear, open, and transparent dialogue between professionals and parents, later including the child as they develop, is important in order to maximise shared learning about DSD and the lifelong impact of this condition for young women. Building collaborations between these young women, parents, and professionals is important in developing comprehensive services that are fit for purpose and able to meet the needs of these young women as they develop through childhood to adulthood.

\section{Conflict of Interests}

The authors declare that there is no conflict of interests regarding the publication of this paper.

\section{Acknowledgments}

The research team would like to thank all the participants in the study. Dr. Caroline Sanders was funded by the National Institute for Health Research Clinical Academic Training Award CL09/17. This paper presents independent research funded by the National Institute for Health Research (NIHR). The views expressed are those of the authors and not necessarily those of the NHS, the NIHR, or the Department of Health.

\section{References}

[1] S. F. Ahmed, J. C. Achermann, W. Arlt et al., "UK guidance on the initial evaluation of an infant or an adolescent with a suspected disorder of sex development," Clinical Endocrinology, vol. 75, no. 1, pp. 12-26, 2011.

[2] B. Köhler, M. Jürgensen, E. Kleinemeier, and M. D. Ute Thyen, "Psychosexual development in individuals with disorders of sex development," in Gender Dysphoria and Disorders of Sex Development, pp. 115-134, Springer, New York, NY, USA, 2014.

[3] V. Pasterski, K. Mastroyannopoulou, D. Wright, K. J. Zucker, and I. A. Hughes, "Predictors of posttraumatic stress in parents of children diagnosed with a disorder of sex development," Archives of Sexual Behavior, vol. 43, no. 2, pp. 369-375, 2014. 
[4] K. Karkazis, A. Tamar-Mattis, and A. A. Kon, "Genital surgery for disorders of sex development: implementing a shared decision-making approach," Journal of Pediatric Endocrinology and Metabolism, vol. 23, no. 8, pp. 789-806, 2010.

[5] I. Mooreland, "The injured world," Differences: A Journal of Feminist Cultural Studies, vol. 25, no. 2, pp. 20-41, 2012.

[6] Z. Kolesinska, S. F. Ahmed, M. Niedziela et al., "Changes over time in sex assignment for disorders of sex development," Pediatrics, vol. 134, no. 3, pp. e710-e715, 2014.

[7] A. Wisniewski, "Gender development in 46,XY DSD: influences of chromosomes, hormones, and interactions with parents and healthcare professionals," Scientifica, vol. 2012, Article ID 834967, 15 pages, 2012.

[8] J. C. Streuli, B. Köhler, K. Werner-Rosen, and C. Mitchell, "DSD and professionalism from a multilateral view: supplementing the consensus statement on the basis of a qualitative survey," Advances in Urology, vol. 2012, Article ID 185787, 8 pages, 2012.

[9] C. Sebastian, S. Burnett, and S. J. Blakemore, "Development of the self-concept during adolescence," Trends in Cognitive Sciences, vol. 12, no. 11, pp. 441-446, 2008.

[10] P. Ekman, "Basic emotions," in Handbook of Cognition and Emotion, T. Dalgleish and M. Power, Eds., John Wiley \& Sons, Sussex, UK, 1999.

[11] S. A. Lewis, J. Noyes, and S. Mackereth, "Knowledge and information needs of young people with epilepsy and their parents: mixed-method systematic review," BMC Pediatrics, vol. 10, article 103, 2010.

[12] M. Paul, D. M. Foreman, and L. Kent, "Out-patient clinic attendance consent from children and young people: ethical aspects and practical considerations," Clinical Child Psychology and Psychiatry, vol. 5, no. 2, pp. 203-211, 2000.

[13] J. Crossley and H. Davies, "Doctors' consultations with children and their parents: a model of competencies, outcomes and confounding influences," Medical Education, vol. 39, no. 8, pp. 807-819, 2005.

[14] M. Fischer and G. Eraut, When Doctors and Patients Talk: Making Sense of the Consultation, The Health Foundation, London, UK, 2012.

[15] S. M. Sawyer, S. Drew, M. S. Yeo, and M. T. Britto, "Adolescents with a chronic condition: challenges living, challenges treating," The Lancet, vol. 369, no. 9571, pp. 1481-1489, 2007.

[16] J. A. Smith, M. Jarman, and M. Osborn, "Doing interpretive phenomenological analysis," Data Analysis, pp. 215-239, 2007.

[17] M. Sandelowski, "What ever happened to qualitative description?" Research in Nursing and Health, vol. 23, pp. 334-340, 2000.

[18] I. A. Hughes, C. Houk, S. F. Ahmed, and P. A. Lee, "Consensus statement on management of intersex disorders," Archives of Disease in Childhood, vol. 91, no. 7, pp. 554-563, 2006.

[19] P. Gee, "Approach and sensibility: a personal reflection on analysis and writing using interpretive phenomenological analysis," Qualitative Methods in Psychology Bulletin, vol. 11, pp. 8-22, 2011.

[20] K. Curtis, K. Liabo, H. Roberts, and M. Barker, "Consulted but not heard: a qualitative study of young people's views of their local health service," Health Expectations, vol. 7, no. 2, pp. 149156,2004

[21] I. Coyne and L. Kirwan, "Ascertaining children's wishes and feelings about hospital life," Journal of Child Health Care, vol. 16, no. 3, pp. 293-304, 2012.
[22] S. R. Grover, "Gynaecological management," in Disorders of Sex Development: An Integrated Approach to Management, J. M. Hutson, G. L. Warne, and S. R. Grover, Eds., pp. 241-248, Springer, 2012.

[23] K. Karkazis, Fixing Sex: Intersex, Medical Authority, and Lived Experience, Duke University Press, 2008.

[24] N. Kimberley, J. M. Hutson, B. R. Southwell, and S. R. Grover, "Well-being and sexual function outcomes in women with vaginal agenesis," Fertility and Sterility, vol. 95, no. 1, pp. 238241, 2011.

[25] S. Kirk, S. Beatty, P. Callery, J. Gellatly, L. Milnes, and S. Pryjmachuk, "The effectiveness of self-care support interventions for children and young people with long-term conditions: a systematic review," Child: Care, Health and Development, vol. 39, no. 3, pp. 305-324, 2013. 


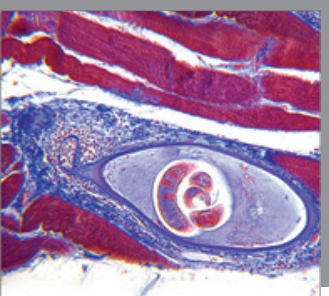

Gastroenterology

Research and Practice
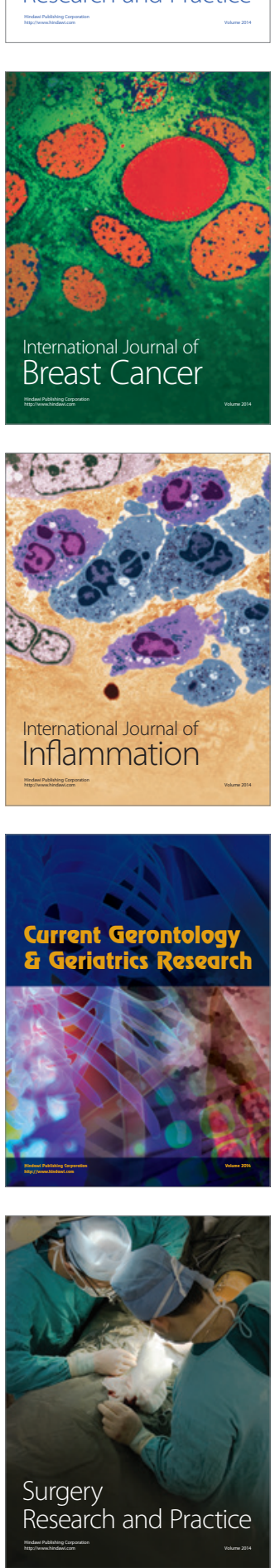

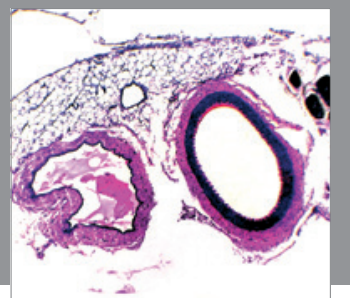

International Journal of Hypertension
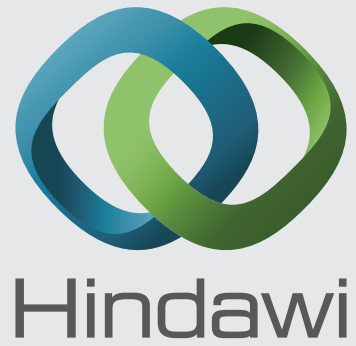

Submit your manuscripts at http://www.hindawi.com
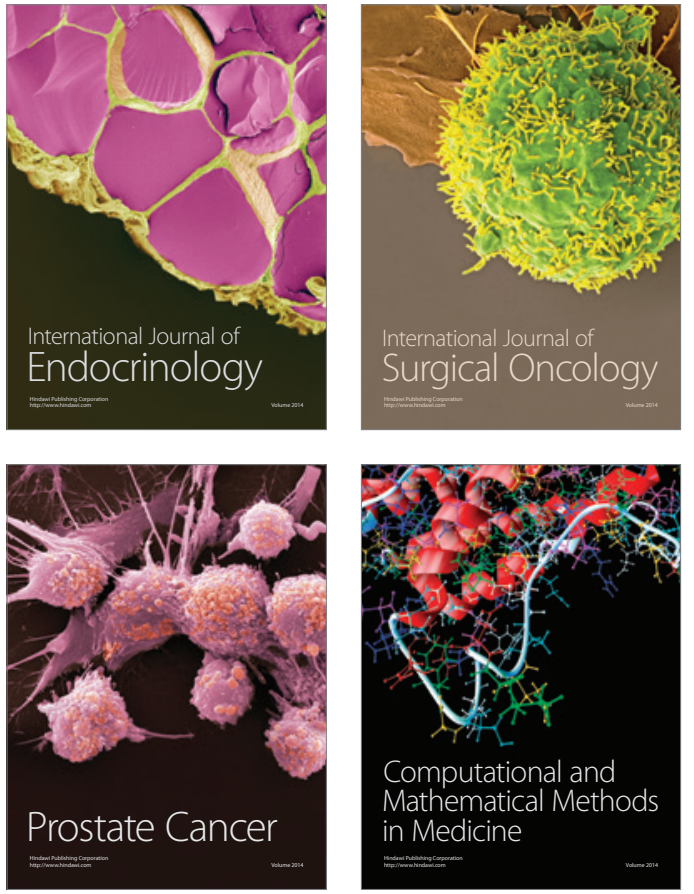
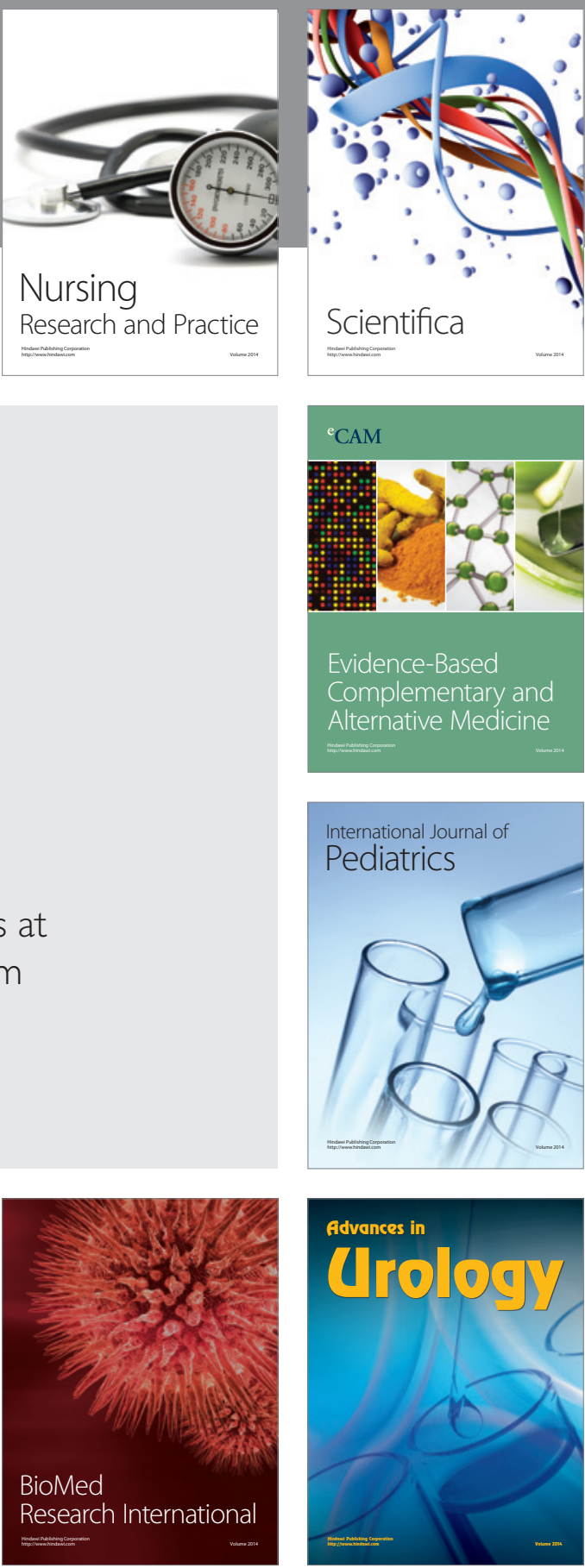

Nursing

Research and Practice

Scientifica

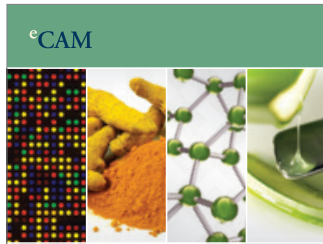

Evidence-Based

Complementary and Alternative Medicine
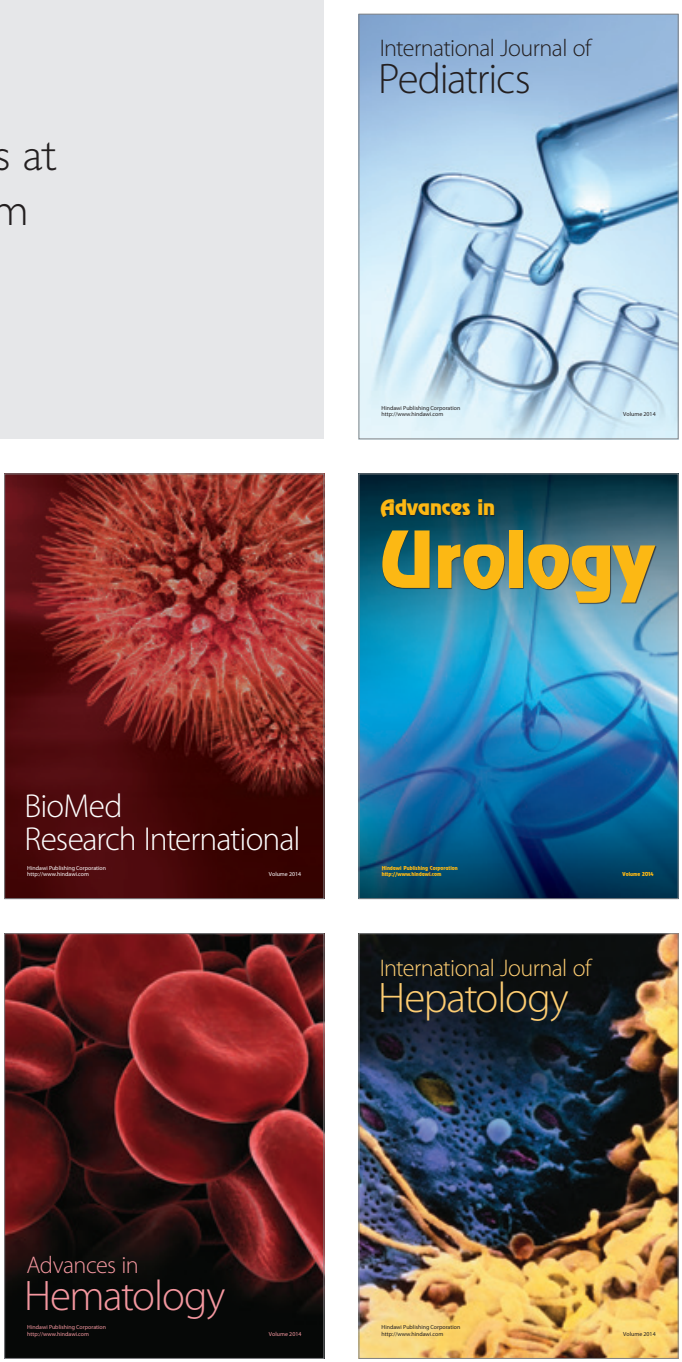